\title{
An Investigation of Determinants of Food Security in Rural Areas of Faisalabad, Pakistan
}

\section{Shahid Mahmood}

\author{
Assistant Professor, Institute of Food Science and Nutrition, University of Sargodha, Pakistan
}

Aqeela Tabassum

Deputy District Officer, Population Welfare Department, Chakwal, Pakistan

Shahbaz Ahmad Khan

Department of Sociology, Arid Agriculture University, Rawalpindi, Pakistan

Norina Jabeen

Department of Sociology, University of Agriculture, Faisalabad, Pakistan

\author{
Doi:10.5901/mjss.2014.v5n4p676
}

\section{Abstract}

Food security exist when all people, all the times have physical and economic access to sufficient, safe and nutritious food to meet their dietary needs and food preference for an active and healthy life. Food security may be analyzed four units at different conceptual level: regions, countries, household and individual. Pakistani people have not enough access to food for their proper nutrition. This study was carried out to investigate the determinants of food security and key issues affecting food security in rural areas of Faisalabad. A sample of 120 household respondents was selected systematically from rural Faisalabad through multistage sampling technique. Study revealed that $63.3 \%$ respondents reported that they had faced the problems regarding the availability of all type of food products and $50.3 \%$ respondents were satisfied about the quality of food. Almost two third of the respondents i.e. 63.3\% claimed that they had not access to access to all type of food products which they want to get. The value of Chi-Square and Gamma showed a significant and strong association between age, education and income of the respondents and their perception about food security.

Keywords: Food security, nutrition, food availability, food preference

\section{Introduction}

Food security can be broadly divided into three main components namely; food availability (Physical access to food), economic access to food and equity of food distribution (Timer, 2000). The number of chronically hungry people was 848 million in 2003 with rose to 923 million in 2007. Given the continued and drastic price rise in staple cereals and oil crops in 2006, a number of people suffering from chronic hunger has increased and is likely to increase further (FAO, 2006). Food insecurity refers to a lack of access to enough food. There are two types of food security: chronic and transitory. Transitory food insecurity is a temporary decline in a household's access to enough food. Chronic food insecurity is a continuously inadequate diet caused by the inability to acquire food (Chakiso and Emana, 2012). In Pakistan, food insecurity remain an unfulfilled dream for currently about 42 million people have not access to enough food. Pakistan is one of the major producers of important agricultural production in the world with a relatively high proportion of undernourished population (26\%). Pakistan is a food secure as well as food sufficient country at the national level. But at the household level 23\% households are food insecure (Bashir et al., 2012). The Nutrition Survey indicated that nearly $43 \%$ of the children are malnutrition, $42 \%$ are under weighted, $37 \%$ stunned, $13 \%$ wasted and $36 \%$ iron deficiency anemia due to the food shortage (GOP, 2002). Food insecurity and consequently food poverty has been on increase over time. The incidence of food poverty is higher in rural areas 35\%, than in urban areas $26 \%$ (United Nation, 2001). The international index score on food security affordability, quality and availability estimates a country's aptitude to feed its people. Out of the 26 developing countries ( $\$ 1,006-3,975$ per capita) countries, Pakistan got 19th place as it scores 38.5 points out of a total of 100 . Sri Lanka and India have performed better than Pakistan by securing 62nd and 66th 
positions on the index. Bangladesh, however, lags behind at 81st place (Jamal, 2012).

Out of 120 districts of rural areas of Pakistan only 40 districts have access to secure food while $80(67 \%)$ are food insecure. Within these food insecure districts, $38(46 \%)$ are extremely food insecure. A number of factors are liable for this situation. The production of wheat, maize, rice, oilseeds, pulses, meat, poultry and fish at the district level are the major indicators of availability of foods. Punjab, KPK, and Baluchistan providence except of Sindh is more likely to be food insecure in the matter of availability. Batter child immunization status, access to safe drinking water and number of hospitals has shown positive effect on food absorption (Azid et al., 2012). According to "National Nutrition Survey" 2011, food insecurity has become one of the major national problems in Pakistan. This report points out that the number of hungry, under nourished and malnourished people raises from 51\% of the country's total population in 2008 to $58 \%$ in 2011.This report further reported that almost $60 \%$ households in Punjab, $72 \%$ in Sindh and $63.5 \%$ in Baluchistan suffered food insecurity. Rising food prices, floods, poverty, armed conflicts, terrorism, energy crisis, economic slowdown and political instability are some of the major factors blamed for rising number of hungry people in the country (NNSP, 2011).

\section{Methodology}

This study was designed to assess the determinants of food security in rural areas of district Faisalabad. There are eight towns in Faisalabad. Four towns represent the rural areas namely Tandalian wala Town, Samundari Town, Chack Jhummara Town and Jaranawala Town. One town Chack Jhummara Town was selected through multistage sampling technique. At the $1^{\text {st }}$ stage on Town out of four rural Town was selected and the $2^{\text {nd }}$ stage two Union Councils ( U.C 3 and12) were selected through simple random sampling technique from the selected rural Town (80 respondents from U.C 3 and 40 respondents from U.C. 12) selected by using proportional sampling technique. And the last stage respondents were selected through systematic sampling technique. Thus 120 respondents were selected from two Union councils.

\section{Results and Discussion}

Table 1 show that socio economic and demographic characteristic of the respondents. Data exhibited that $38.3 \%$ of the respondents belonged to 18 to 25 year age group, indicated that the healthy participation of youth in this survey. Majority of the respondents $48.3 \%$ belonged to 26 to 40 year age group, while the remaining $18.3 \%$ respondents belonged to 42 and above year age group. Data indicated that majority of the respondents $87.5 \%$ were female. Data demonstrated that majority of the respondents $45 \%$ were illiterate, whilst the $23.3 \%$ respondents had 1 to5 grade education. $17.5 \%$ and $14.2 \%$ respondents had 6 to 10 grade and 11 and above grade education respectively. 21.7\% respondent's income were up to 10,000 rupees, while majority $43.3 \%$ of the respondent's income were in between 10001 to 20000 rupees and more than one third i.e. 35\% had above R.s 20000 hose hold monthly income.

Table 1. Socio economic and demographic characteristic of the respondents

\begin{tabular}{|c|c|c|}
\hline Age of the respondents & Frequency & Percentage \\
\hline 18 to 25 & 46 & 38.3 \\
\hline $26-40$ & 52 & 48.3 \\
\hline 41 and above & 22 & 18.3 \\
\hline \multicolumn{2}{|c|}{ Sex of the respondents } \\
\hline Male & 15 & 12.5 \\
\hline Female & 105 & 87.5 \\
\hline Educational Level \\
\hline 1titerate 5 Grade & 54 & 45.0 \\
\hline 6-10 Grade & 28 & 23.3 \\
\hline 11 and above grade & 21 & 17.5 \\
\hline Household monthly income (Rupees) \\
\hline Up to 10000 & 26 \\
\hline 10001-20000 & 52 & 21.7 \\
\hline 20001 and above & 42 & 43.3 \\
\hline \multicolumn{2}{|c|}{} \\
\hline
\end{tabular}


One third of the respondents i.e. 33.3\% were consonance of this statements that the "all type of food products available in their area", while the same proportion of the respondents $33.3 \%$ reported that there were not access on the proper availability of food products in their areas. About $20.0 \%$ and $13.3 \%$ of the respondents told that food products were available often and some times respectively. Data shows that majority of the respondents $63.3 \%$ reported that they have not access on all type of foods products which we want to get in our areas. More than one third of the respondents i.e. $36.7 \%$ were in the opinion that, they had access on the availability of all type of food products in their areas. Data show that 53.3\% respondents were satisfied with the quality of food which they bought from their surrounding areas, while $46.7 \%$ respondents were not satisfied about the quality of food. Arene and Anyaeji, (2011) found that about 60 per cent of the households were food insecure Nsukka metropolis of Enugu State, Nigeria. Data show that as far as eating habits of the respondents concerned $13.3 \%$ were eat two time in a day, whilst, a large majority $82.5 \%$ respondents were eat meal in 3 times in a day. A small proportion of the respondents $4.2 \%$ were eat the meal more than three times in a day. Saleem, (2011) argued that about 58\% of the households were food-insecure in Pakistan and, among them, $28.4 \%$ were food-insecure without hunger, $19.8 \%$ with moderate hunger and $9.8 \%$ were food insecure with severe hunger. In urban areas, about $48 \%$ were food secure while $52 \%$ were food insecure, compared with rural areas where $39.4 \%$ of households were food secure and $60.6 \%$ were food insecure. On thing is to be noted here that this research was conducted in rural areas where the natural food i.e. milk, butter and eggs are easily available but only 30.8 respondents were in the opinion that family members took milk regularly and majority $69.2 \%$ of the respondent's family member had not access to milk regularly. Wasif, (2011) a famous analyst pointed out that $57 \%$ of the households in Pakistan were facing food insecurity. In these households, $50 \%$ of the women and children were found to be malnourished. These statics shows that that the maternal and child malnutrition is a major issue for Pakistani people till now.

Table 2: Distribution of the respondents with regard to availability, accessibility and satisfaction with the quality of food products

\begin{tabular}{|c|c|c|c|}
\hline & Response categories & Frequency & Percentage \\
\hline 1 & \multicolumn{3}{|c|}{ All types of food products available in your area } \\
\hline i. & Yes & 40 & 33.3 \\
\hline ii. & No & 40 & 33.3 \\
\hline iii. & Often & 24 & 20.0 \\
\hline iv. & Some time & 16 & 13.3 \\
\hline 2 & \multicolumn{3}{|c|}{ Accessibility of food products which you want to get } \\
\hline i. & Yes & 44 & 36.7 \\
\hline ii. & No & 74 & 63.3 \\
\hline 3 & \multicolumn{3}{|c|}{ Satisfaction with the quality of food } \\
\hline i. & Yes & 64 & 53.3 \\
\hline ii. & No & 56 & 46.7 \\
\hline 4 & How many time eat meal in a day & & \\
\hline i. & Two & 16 & 13.3 \\
\hline ii. & Three & 99 & 82.5 \\
\hline iii. & More than three & 5 & 4.2 \\
\hline 5 & \multicolumn{3}{|c|}{ Family members take milk regularly } \\
\hline & Yes & 37 & 30.8 \\
\hline & No & 83 & 69.2 \\
\hline 6 & \multicolumn{3}{|c|}{ Bought wheat for the whole year } \\
\hline & Yes & 69 & 57.5 \\
\hline & No & 51 & 42.5 \\
\hline 7 & \multicolumn{3}{|c|}{ Income spent on buying their food } \\
\hline & Up to 10000 & 54 & 45 \\
\hline & $10001-15000$ & 44 & 36.7 \\
\hline & 15001 and above & 22 & 18.3 \\
\hline 8 & \multicolumn{3}{|c|}{ Knowledge about balance diet } \\
\hline & Yes & 70 & 58.3 \\
\hline & No & 50 & 41.7 \\
\hline
\end{tabular}

Data show that $57.5 \%$ respondents were purchased wheat for the entire year while $42.5 \%$ respondents could not purchased wheat for the whole year. Data exhibited that $45 \%$ respondents spent their income on food up to 10000 
rupees per month, while the $36.7 \%$ respondents spent 10001 to 15000 rupees per month on purchasing food. These findings show that a bulky share of monthly household income was allocated for purchasing the food item in rural areas. One thing is to be very astonished that in rural areas $58.3 \%$ respondents had knowledge about the balance diet while $41.7 \%$ respondents had no any idea about the balance diet.

Table3: Association between age of the respondents and their knowledge bout food security

\begin{tabular}{|c|c|c|c|c|}
\hline \multirow{2}{*}{ Age of the respondents } & \multicolumn{2}{|c|}{ Knowledge about food security } & \multirow{2}{*}{ Total } \\
\cline { 2 - 4 } & Low & Medium & High & \\
\hline Up to 25 Years & $2(3.8 \%)$ & $7(13.5 \%)$ & $43(82.7 \%)$ & $52(43.3 \%)$ \\
\hline $26-40$ & $10(21.7 \%)$ & $8(17.4 \%)$ & $28(60.9 \%)$ & $46(38.3 \%)$ \\
\hline 40 and above & $2(9.1 \%)$ & $8(36.4 \%)$ & $12(54.5 \%)$ & $22(18.4 \%)$ \\
\hline Total & $14(11.7 \%)$ & $23(19.2 \%)$ & $83(69.2 \%)$ & $120(100.0 \%)$ \\
\hline
\end{tabular}

Chi-square $=13.71 ;$ Degree of freedom $=4 ;$ P-value $=.008 ;$ Gamma value $=-.394$

Table 3 shows highly significant association between age of the respondents and their knowledge about food security was found. Gamma value shows a strong negative relationship between variables. Data reveals that young adults had more knowledge and awareness about food security as compared to older respondents. Similar findings found by the, Arene and Anyaeji (2011) they pointed out that employed status and older household heads tend to be food more food secure. Table 5 shows a highly significant association between income of the respondents and their knowledge about food security

Table4: Association between education of the respondents and their knowledge about food security

\begin{tabular}{|c|c|c|c|c|}
\hline \multirow{2}{*}{ Education of the respondents } & \multicolumn{2}{|c|}{ Knowledge about food security } & \multirow{2}{*}{ Total } \\
\cline { 2 - 4 } & Low & Medium & High & \\
\hline Illiterate & $7(77.8 \%)$ & $1(11.1 \%)$ & $1(11.1 \%)$ & $9(7.5 \%)$ \\
\hline Up to 8 Grade & $4(15.4 \%)$ & $10(38.5 \%)$ & $12(46.2 \%)$ & $26(21.7 \%)$ \\
\hline 12 Grade & $1(5.3 \%)$ & $7(36.8 \%)$ & $11(57.9 \%)$ & $19(15.8 \%)$ \\
\hline 14 Grade and above & $2(3.0 \%)$ & $5(7.6 \%)$ & $59(89.4 \%)$ & $66(55 \%)$ \\
\hline Total & $14(11.7 \%)$ & $23(19.2 \%)$ & $83(69.2 \%)$ & $120(100.0 \%)$ \\
\hline
\end{tabular}

Chi-square $=78.04 ;$ Degree of freedom $=6 ;$ P-value $=.000 * * ;$ Gamma value $=0.781$

Table 5: Association between income of the respondents and their knowledge about food security

\begin{tabular}{|c|c|c|c|c|}
\hline \multirow{2}{*}{ Income of the respondents in (R.S) } & \multicolumn{2}{|c|}{ Knowledge about food security } & \multirow{2}{*}{ Total } \\
\cline { 2 - 4 } & Low & Medium & High & \\
\hline Up to 10000 & $8(30.8 \%)$ & $8(30.8 \%)$ & $10(38.5 \%)$ & $26(21.7 \%)$ \\
\hline 10001-20000 & $6(11.5 \%)$ & $6(11.5 \%)$ & $40(76.9 \%)$ & $52(43.3 \%)$ \\
\hline 20001 and above & - & $9(21.4 \%)$ & $33(78.6 \%)$ & $42(35 \%)$ \\
\hline Total & $14(11.7 \%)$ & $23(19.2 \%)$ & $83(69.2 \%)$ & $120(100.0 \%)$ \\
\hline
\end{tabular}

Chi-square $=21.08 ;$ Degree of freedom $=4 ;$ P-value $=.000 * * ;$ Gamma value $=0.475$

Table 4 shows that Chi-square value (78.04) highly significant association between education of the respondents and their knowledge about food security. It means illiterate people had less knowledge as compared to educated respondents. Sultan and Kiani (2011) also described that the batter educational level of household's head had also important and positive impact on food security. Place of residence (Urban) had an imperative and negative effect on household's food security. While social capital and service structure of the respondents did not affect household's food security. In table 5 gamma values (0.47) shows also a strong positive relationship between dependent and independent variables. The finding of Bashir et al., (2012) strongly line up with present study they examined that monthly income, livestock, joint family system and batter educational levels were positively impact on rural household food security. From another point of view, greater household heads' age and family size had negative impacts on household food security. 


\section{Conclusion}

The preponderance of household food insecurity in the study localization was high and distressing. In rural areas of study zone majority of the people had not proper access to food and mostly respondents reported that non-proper availability of food products in their area. It was found that majority of the people had low purchasing power. Due to the low purchasing power people especially children were suffering malnutrition, anemia and other communicable diseases. It is suggested that government should pay proper attention for physical and economic access to sufficient food for adequate dietary needs for every citizen.

\section{Reference}

Arene, C. J. and R. C. Anyaeji. 2011. Determinants of Food Security among Households in Nsukka Metropolis of Enugu State, Nigeria. Pakistan Journal of Social Sciences. 30(1): 9-16

Azid, T., R. E. A. Khan, M. U.Toseef. 2012. Determinants of Food Security in Rural Areas of Pakistan. International Journal of Social Economics. 39(12)

Bashir, M. K., Schilizzi, S. and Pandit, R. (2012) The determinants of rural household food security in the Punjab, Pakistan: an econometric analysis, Working Paper 1203, School of Agricultural and Resource Economics, University of Western Australia, Crawley, Australia.

Chakiso, K.T. and B. Emana. Household Food Insecurity, Coping Strategies and Policy Options: Food Insecurity Causes and Coping Strategies among Farm Households in Dodota-Sire District, Arsi Zone. Lambert Academic Publishing, Germany.

FAO. 2006. THE State of Food Security in the World. Food and Agricultural Organization, Italy, FAO 2006.

GOP. 2002. Government of Pakistan. National Nutrition and Health Survey. Ministry of Health Government of Pakistan, Islamabad.

Jamal, N. 2012. Ranking in food security index. "The Dawn News". 13th August, 2012. Available at. http://dawn.com/2012/08/13/ranking-in-food-security-index/. Accessed date 12/09/2012

NNSP. 2011. National Nutrition Survey Pakistan. Nutrition Wing, Cabinet Division, Government of Pakistan, Islamabad.

Saleem, M. 2011. Nutrition Survey 2011 report: About 58 percent of households are food-insecure in Pakistan. Retrieved Date 27/09/2012. Available at http://www.brecorder.com/general-news/single/599/172/1254523

Sultana, A. and A. Kiani. 2011. Determinants of food security at household level in Pakistan. African Journal of Business Management. 5(34): 12972-79.

Timer, C. P. 2000. The Macro Dimension of Food Security: Economic Growth, Equitable Distribution and Food Price Stability. Food Policy. 25(1):283-295.

Wasif, S. 2011. National Nutrition Survey 2011: Food insecurity affecting 60\% of women and children. Published in The Express Tribune, September 18th, 2011. 